BULL. AUSTRAL. MATH. SOC.

VOL. 12 (1975), 480.

\title{
Free products of topological groups: Corrigendum
}

\section{Sidney A. Morris}

Professor Edward T. Ordman has pointed out to the author that the proof of Theorem 2.2 in [2] is incorrect. The theorem is, in fact, correct and was proved by Graev [1]. The incorrect proof presented in my paper has been modified by Ordman [3] to provide a much simpler proof than Graev's in a special case.

\section{References}

[1] М.И. Гравв [M.l. Graev], "О свободных пронзведениях топологнчесних групп" [On free products of topological groups], Izv. Akad. Nauk SSSR Ser. Mat. 14 (1950), 343-354.

[2] Sidney A. Morris, "Free products of topological groups", BulZ. Austral. Math. Soc. 4 (1971), 17-29.

[3] Edward T. Ordman, "Free products of topological groups with equal uniformities, I", Colloq. Math. 31 (1974), 37-43.

School of Mathematics, University of New South Wales, Kensington, New South Wales. 